\title{
Standardisation or Resilience? \\ The Paradox of Stability and Change in Patient Safety
}

Pedersen, Kirstine Zinck

Document Version

Accepted author manuscript

Published in:

Sociology of Health and IIIness

DOI:

10.1111/1467-9566.12449

Publication date:

2016

License

Unspecified

Citation for published version (APA):

Pedersen, K. Z. (2016). Standardisation or Resilience? The Paradox of Stability and Change in Patient Safety. Sociology of Health and IIIness, 38(7), 1180-1193. https://doi.org/10.1111/1467-9566.12449

Link to publication in CBS Research Portal

\section{General rights}

Copyright and moral rights for the publications made accessible in the public portal are retained by the authors and/or other copyright owners and it is a condition of accessing publications that users recognise and abide by the legal requirements associated with these rights.

Take down policy

If you believe that this document breaches copyright please contact us (research.lib@cbs.dk) providing details, and we will remove access to the work immediately and investigate your claim. 


\title{
Standardisation or Resilience?: The Paradox of Stability and Change in Patient Safety
}

\section{Kirstine Zinck Pedersen}

\author{
Journal article (Post print version)
}

This is the peer reviewed version of the following article: Standardisation or Resilience? : The Paradox of Stability and Change in Patient Safety. / Zinck Pedersen, Kirstine. In: Sociology of Health and IIIness, Vol. 38, No. 7, 11.07.2016, p. 1180-1193, which has been published in final form at http://dx.doi.org/10.1111/14679566.12449. This article may be used for non-commercial purposes in accordance with Wiley Terms and Conditions for Self-Archiving.

Uploaded to Research@CBS: October २०16 


\section{Standardisation or resilience? The paradox of stability and change in patient safety}

This paper explores an apparent paradox of stability and change in patient safety thinking and practice. The dominant approach to patient safety has largely been focused on closing 'safety gaps' through standardisation in seemingly stable healthcare systems. However, the presupposition of system stability and predictability is presently being challenged by critics who insist that healthcare systems are complex and changing entities, thereby shifting focus towards the healthcare organisation's resilient and adaptive capacities. Based on a close reading of predominant patient safety literature, the paper analyses how a separation between stability and change is articulated in ontological, historical, and situated terms, and it suggests the way in which predetermining healthcare settings as either stable or unstable paves the way for a system-engineering approach to patient safety that pre-empts certain types of safety solutions. Drawing on John Dewey's influential ideas about the interconnectedness of stability and change, this prescriptive perspective is discussed and challenged. It is suggested that only by rethinking the relationship between change and stability can patient safety efforts begin to address the uncertainty of medical practice as well as the necessary competences of healthcare professionals to act with 'safety dispositions' as a precondition for delivering safe care.

\section{Introduction}

After almost two decades in the international health politics scene, the dominant mode of patient safety thinking and practice is at a threshold, and a new approach has emerged. The promoters of the new perspective on patient safety have named it Safety 2.0, the New View, Resilient Safety or simply Safety II, and they argue that two opposite types of answers to the important question of patient safety in healthcare prevail: the orthodox view, Patient Safety I, which is based on seminal reports from 2000 (Department of Health 2000; Kohn et al. 2000), in which healthcare systems are understood as essentially stable and predictable and standards are the obvious solution to prevent errors. In contrast, Patient Safety II conceives of healthcare systems as unstable, complex and mutable, in which adaptability, flexibility and robustness are the focus (e.g., Hollnagel et al. 2013, 2015; Braithwaite 2015). The relationship between the old and new view is sometimes proposed as one of substitution and sometimes as one of supplementation, but what is apparently agreed upon is the basic assumption that the complexity of current healthcare systems requires safety scientists to start thinking radically differently about how to create and sustain a safe and resilient healthcare system for patients.

The two modes of patient safety are constructed as opposites according to an apparent paradox of stability and change, which arises due to dichotomizations of concepts such as rules and flexibility, 
1 linearity and complexity, routine and variation that are all largely understood as separate and oppositional traits of organisation. The separation of stability and change is not specific to patient safety, and it has played a central role in organisational research in which the idea that bureaucracy, rules and standardisation are preferred in stable settings, while flexibility and variation is predominantly seen as necessary in complex and changing environments (e.g., March 1991; Weick \& Quinn 1999). Recently, this proposition has been challenged by a number of social scientists and organisational theorists who have argued that stability and change should be understood as a duality rather than a dualism; that is, it should be understood as something that is analytically separable but empirically interdependent, complementary and mutually enabling (Levinthal \& Rerup 2006; Sutcliffe et al. 2004; Farjoun 2010; see also Dewey 2017). Many of these studies are inspired by American pragmatist John Dewey's (1859-1952) warning about dichotomisation between stability and precariousness, as well as his practical argument about the interrelationship between stability and change, not least in human habits and dispositions.

In this paper, I suggest that to address the important issue of patient safety, we need to understand and attend to the apparent paradox of stability and change implied in the oppositional status of dominant modes of patient safety; that is, the assumption that stability and change can be meaningfully separated as a precondition for safety science and system improvements. Through a close reading of newer patient safety literature primarily within the Safety II tradition, this paper shows how a separation of stability and change in patient safety thinking is established through the use of ontological, historical and situated arguments. It is concurrently shown how this separation paves the way for a systemengineering perspective on safety management, which tends to prescribe certain types of safety solutions. In the last part of the paper, I discuss some pertinent challenges regarding the separation of stability and change in safety management. With reference to earlier sociological studies of medical error (Fox 1957; Paget 1988) and social science alternatives to mainstream patient safety literature (e.g., Mesman 2008; Zuiderent-Jerak et al. 2007, 2015; Iedema \& Carroll 2012; Jerak-Zuiderent 2012), the paper argues that to deliver safe care, the inseparability and connectedness of stability and change and the uncertainty of medical practice must be taken into account. This is done by, among other things, focusing more on the medical practitioner's safety habits and dispositions in addition to the present patient safety ideal of system reengineering.

\section{Background}

The international patient safety agenda has become increasingly dominant in Western healthcare institutions since it was initiated in the early 1990s and solidified by the influential American Institute of 
1 Medicine's report, To Err is Human (Kohn et al. 2000), and the British equivalent, An Organisation with a 2 Memory (Department of Health 2000). Under the heading of organisational learning, systems thinking, 3 Human Factors, and 'non-blame', massive coordinated international efforts have followed these seminal statements which have led to the introduction of non-sanctioning incident reporting systems, incident analysis tools, and a wide range of safety systems and procedures that are primarily imported from high-risk industries and are developed and promoted by leading healthcare organisations such as the WHO, the American Institute of Medicine, and the American-based accreditation organisation The Joint Commission (www.jointcommission.org). With the help of national and international patient safety organisations, these major global players assist in securing a high level of standardisation across countries.

By envisioning healthcare as a relatively stable and simple system where safety concerns the elimination of the future risk of error, the dominant safety management vision has standardisation and 'rule-based solutions' (McDonald et al. 2006) at its heart: Reducing performance variability through the introduction of guidelines, checklists, targeted safety systems, failsafe procedures and reporting systems has been the main objective of patient safety management efforts. With the increasing prominence of Safety II, the dominance and the benefits of this standardisation agenda have been questioned, especially by stressing the problems of understanding safety management as closing safety gaps through linear cause and effect thinking and component failure models (e.g., Nemeth et al. 2008; Jeffcott et al. 2009; Sheps \& Cardiff 2011; Hollnagel et al. 2013, 2015; Baithwaite et al. 2015). Instead of thinking of safety in terms of reliability, Safety II thinking promotes robustness or resilience as the ability for complex systems to adjust their functioning and sustain their operations even during disturbances and in the presence of continuous stress in a constantly changing environment. This understanding of the resilience concept has been developed in the field of ecology (Holling 1973), and apart from its growing impact on safety science in general (e.g., Hollnagel et al. 2006; Weick \& Sutcliff 2007), it has had a strong impact on crisis adaptation, security response research and practices, and recently, finance (Walker \& Cooper 2011).

Although the full enactment of Safety II in terms of a systematic implementation of new types of safety management systems and technologies has yet to be seen, it currently appears that the resilience engineering approach has the potential to form a counter-movement to the standardisation agenda. Its success is visible in the growing number of articles and books about resilience engineering in 31 healthcare, the increasing number of courses, workshops, and conferences organised around this theme, and initiatives such as the Resilient Health Care Net and its corresponding website 
1 (www.resilienthealthcare.net), which has been created to "take a lead in applying resilience engineering to health care worldwide" (RHCN 2016).

\section{The paradox of stability and change}

4 Since at least Heraclitus's introduction of the doctrine of flux in antiquity, the paradox of stability and change (or flux and logos) has existed throughout philosophical thought and later through social and organisational studies in a host of different disguises. The paradox of stability and change relates to similar apparent paradoxes, such as those of linearity and complexity, rules and flexibility, order and freedom, and routine and variation, and it has been determined to be one of the most central paradoxes of organisation and administration (Farjoun 2010). An early but strikingly precise diagnosis of the paradox of stability and change comes from John Dewey, who spent most of his career opposing the spread and consequences of a priori metaphysical dichotomies between mind and body, true and false, means and aim, etc. Hence, much of Dewey's writing is structured as examinations and rejections of dichotomies not to substitute one side of the dichotomy with the other nor reduce, merge or make the two side of the dichotomy equal but to insist that divisions, differences or tensions are always empirical and emerging and never absolute. Dewey argues that most dichotomising returns to an ontological controversy between stability and change in philosophy:

"One of the striking phases of the history of philosophical thought is the recurrent grouping together of unity, permanence (or the eternal), completeness and rational thought, while upon another side full multiplicity, change and the temporal, the partial, defective, sense and desire. This division is obviously but another case of violent separation of the precarious and unsettled from the regular and determinate" (Dewey 1925: 65)

As such, Dewey compares a classic orthodox philosophical view - where stability is understood as ontologically primary - with a growing number of what he characterises as "philosophies of flux" (1925: 50). Here, change is understood as ontologically primary. As for the classic philosophical view, Dewey argues that it has been commonplace to identify reality with the "sure, regular and finished" (1925: 47), whereby philosophy has largely come to "deny the existence of chance, to mumble universal and necessary law, the ubiquity of cause and effect, the uniformity of nature" (1925: 44). These metaphysical presumptions are closely linked to the development of science, technologies of control, and powers of prediction. At the other side of the spectrum "philosophers of becoming" (Dewey 1925: 50) count a group of philosophers, from Heraclitus and Hegel to Bergson, who insist (together with Dewey) that "the world of empirical things includes the uncertain, unpredictable, uncontrollable and hazardous" (1925: 42). However, this empirical fact is quickly turned into a new type of absolutism; by 
1 defining the world in general as a scenario of risk that is inherently and a priori uncertain, unstable and irregular, the philosophers of flux end up defining change in a way similar to the orthodox view, namely by also making change and flux 'universal, regular, sure' (Dewey 1925: 50). Therefore, the philosophers of becoming largely proposed a metaphysic of change that presents us with prescription rather than with description (Dewey 1925: 51). Instability, flux, and change become something that is glorified for its own sake rather than an empirical fact whereby it ceases to be "a call to effort, a challenge to investigation" (1925: 51).

Dewey argues that in our quest to create dichotomies of the world, including the tendency to separate stability and change - and to predetermine one as more primary (or worthy) than the other - we fail to recognise the fact that the world is neither inherently stable or unstable but is rather inherently stable and unstable; the world is an "inextricable mixture of stability and uncertainty" (1925: 45):

"We live in a world which is an impressive and irresistible mixture of sufficiencies, tight completenesses, order, recurrences which make possible prediction and control, and singularities, ambiguities, uncertain possibilities, processes going on to consequences as yet indeterminate." (Dewey 1925: 47)

Although we might recognise the stable and the precarious separately in analyses, the two traits are practically indivisible and intrinsically related insofar that "change gives meaning to permanence and recurrence makes novelty possible" (Dewey 1925: 47). Dewey has been criticised here for delivering a new metaphysics of generic traits of existence, which reveals a search for synthesis and therefore accentuates an underlying Hegelianism. However, as noted by Harris (2007), Dewey's ideas of the inseparability of the stable and the precarious should not be understood separately from his more practical writings on education and learning. Most notably, perhaps, the interconnectedness and mutual dependency between stability and change is a vital part of Dewey's notion of habits. To Dewey, habits refer to "the kind of human activity which is influenced by prior activity and is in that sense acquired" (Dewey 1922: 42). As such, habits refer broadly to our 'stored' patterns of action and thinking that have become stabilised over time to save us time by choosing the best possible courses of action based on earlier experiences. Thus, habits are not mindless routines but are often flexible and dynamic dispositions to act in certain experience-based ways adaptable to the particularities of the actual situation. In this way, habits are both stable and adaptable, and to Dewey, the quest is to nurture and create 'intelligent habits' that retain their stability while at the same time remaining adaptable to the particular context. 
Much like Dewey, the goal of a number of recent studies has been to dismantle what seems to be an apparent paradox of stability and change, which is apparent because it only arises, as Farjoun (2010) argues in his article entitled 'Beyond Dualism: Stability and Change as a Duality', when the two concepts are defined as opposites and separate as is largely the case within organisational studies. Here, it is often assumed that "stability and change, and the practices, processes, and forms that support them, are largely incompatible and mutually exclusive" (Farjoun 2010: 202). This leads to familiar dichotomies such as exploitation and exploration (March 1991), episodic and continuous change (Weick \& Quinn 1999) as well as the prevailing idea that bureaucracy, standardisation and rational design work well in stable settings and for specialised tasks, while more organic and flexible structures are required in changing environments and for complex and non-routine tasks. Although such perspectives often recognise that stability and change are both needed, the line of reasoning is generally founded on a dichotomising idea of separation and opposition between stability and change. In recent debates, the pragmatic quest to overcome this separation is echoed, and it is increasingly suggested that approaching organisational design through the paradox of stability and change is too restrictive to capture the complexity of organisational reality where change and stability are often interdependent, complementary and constituent of each other (Sutcliffe et al. 2004; Levinthal \& Rerup 2006; Farjoun 2010). With Dewey as a frequent source of inspiration, the attempt to overcome the tendency to think of stability and change as separate and oppositional organisational qualities has been particularly noticeable in the discussion on routines and habits in organisational life (e.g., Feldman \& Pentland 2003; Cohen 2007).

\section{Ontological, historical or situated arguments of separation}

In a self-acclaimed attempt to 'turn patient safety on its head' (Braithwaite et al. 2015), the resilience perspective on patient safety is mobilising a large amount of 'from-to' arguments: from probability to variability, from resultant to emergent, from prevention to adaptability, from stability to flux, from linearity to complexity, from closed systems to open systems and from failures to 'what goes right'. In itself, this oppositional stance of the resilience perspective contributes to the establishment of a paradox of stability and change in present safety management thinking. However, it seems that the particular expression of the paradox comes in at least three versions, which are all variations of what, within recent discussions of safety science, have been determined as a question of 'complementarity or substitution' between Safety I and II (Hale 2014: 67).

31 The most simplified version of the assumption is based on an idea of ontological substitution. Here, ontological arguments of an essentially complex, fluctuating and unpredictable world are used to 
promote a radical substitution of older conceptual tools with new ones. Safety is achieved "not by adding one more concept to the existing vocabulary, but by proposing a completely new vocabulary, and therefore also a completely new way of thinking about safety" (Hollnagel et al. 2006: 2). As part of the ontological substitution argument, healthcare is often described in general as "a complex adaptive system (CAS) - or even an autopoietic system" (Hollnagel et al. 2013: 229). Here, standardisation is understood not only as potentially inefficient but counterproductive as it can lead to a system in which even slight disruptions can render it dysfunctional. The change in the ontological foundations of safety modes is often argued by turning to complex system theory, but broader metaphysical arguments are also implemented, as when Dekker (2011), for example, argues that orthodox safety efforts are dominated by a "Newtonian ethic of failure" (Dekker 2011: 76), which is "not helpful for meaningfully modeling the messy, constantly changing, kaleidoscopic interiors of organizational life where failures and successes are spawned" (Dekker 2011: 64). Therefore, Dekker argues, safety science should look to postmodernism, complexity theory and chaos theory in the quest to establish a new world view - a second family of explanations - to replace the former 'modern' world-view. With the introduction of this 'new world view', a substitution of stability with change is done in a manner not far from what Dewey determined as a Bergsonian metaphysics of change (Dewey 1925; see also Du Gay \& Vikkelsø 2012).

The second version of the argument is one of historical replacement between Safety I and II based on a 'before and after' structure, where it is suggested that healthcare systems are moving historically from simple structures to more complex ones. It is argued, for example, that the assumptions of Safety I does "not fit today's world, neither in industries nor in health care" (Hollnagel et al. 2015: 4) because on the one hand, healthcare settings have become increasingly complex, and on the other hand, healthcare organisations have been subjected to 'a tsunami' of constant change imperatives (Hollnagel et al. 2015: 16). With increased instability, change and complexity, the linear cause-effect explanations of failures and unwanted system outcomes are no longer viable. Within this line of reasoning, it is, for example, stated that simple linear accident models are "well-suited to situations that resemble what work was like in the 1920s and 1930s" (Hollnagel et al. 2015: 23) and that composite linear models (such as James Reason's popular Swiss cheese model, 1990) were suitable in the 1970s and 1980s "but not the 2000s and beyond" (Hollnagel et al. 2015: 23). Hence, it is summarised that "Models and methods which require that systems are linear with resultant outcomes cannot and should not be used for non-linear systems where outcomes are emergent rather than resultant" (Hollnagel et al. 2015: 23). Although the argument here is historical rather than an ontological, the result is often also one of 
substitution: Older linear models of safety need to be substituted with new ones based on principles of resiliency.

3 The third version of the stability-change argument, which I have entitled the situated separation 4 argument', involves an understanding of complementary between Safety I and II. The complementary approach is generally based on the realisation that some organisational settings are dominated by simple structures and some by complex ones - and that although organisational complexity might be increasing, some types of organisation are still founded on stable conditions, well-defined tasks and a high degree of predictability, in which case Safety I thinking and tools are still viable. It is often simply suggested that "[t]he way forward [...] lies in combining the two ways of thinking" (Hollnagel et al. 2015: 5) or that "Safety-II is intended as a complement to Safety-I rather than as a wholesale replacement. The two perspectives on safety must co-exist, at least for the foreseeable future" (Braithwaite et al. 2015). This last quote also indicates how the three positions - ontological, historical and situated - are often stated simultaneously by the same authors, are somewhat confused or overlapping, or are ambivalently expressed. In this case, the situated position is challenged by a historical substitution argument by the inserted 'for the foreseeable future'.

\section{Engineering system safety by way of separation}

17 The separation of stability and change - whether argued by way of ontological, historical or more 18 situated positions - has practical consequences for the way safety management is conceived and for 19 what safety technologies are preferred. It is largely the description of the healthcare system as complex 20 that enables the Safety II approach to maintain the system-reengineering optimism that is characterised 21 as one of the most important features of the seminal reports of the patient safety movement (See Jensen 2008; Pedersen 2013). This general faith in system engineering might help explain why the solutions proposed by the two patient safety positions are not radically different despite the fact that their understanding of the system in question are oppositional.

Although the early reports actively referred to more complex systems theories, the particular understanding of systems thinking in Safety I that is expressed in the safety technologies introduced is one in which healthcare is largely understood as a relatively closed, stable, and predictable system that is able, through clever system design, to become failsafe. Moreover, by drawing on an often rather simplified version of Human Factors research, it is largely argued that humans err because of their fallible cognition, imperfect information processing abilities, limited attention span, etc. Therefore, in contrast to systems, humans are understood as essentially unsafe, hence the expression 'to err is human' 
1 (Kohn et al. 2000). Consequently, standardised systems need to be in place to ensure that human 2 variability and fallibility is reduced. The main patient safety technologies of the Safety I approach are all 3 largely based on this stability and prevention scheme. This includes standards, checklists, controls, audits and critical incident reporting, which has been a dominant part of the patient safety agenda from its inception. Moreover, incident analysis technologies, such as the Root Cause Analysis, almost serves as the epitome of Safety I's systems perspective, as such technologies are supposed to "provide causal information to facilitate learning from serious adverse events and near misses and to produce an action plan to prevent recurrence where possible and reduce risks to future patients" (Department of Health 2001: 34; see also Pedersen 2013).

Advocates of the resilience approach argue that although it "has been popular to believe that this development has brought us systemic thinking about safety (...) it hasn't”' (Dekker 2011: 58). Safety II's more 'correct' version of systems thinking therefore rejects the 'causality credo' (Hollnagel et al. 2015: 13) of Safety I, as it seeks to introduce new safety solutions in line with an understanding of healthcare systems as non-linear, open and complex systems. Although the actual form of such new resilience solutions is not always described, some suggestions have been given. On the one hand, these include reengineering initiatives, where standardisation as the guiding organisational principle has been substituted with flexibility or slack. Rearrangements, such as the design of flexible spaces, is suggested: "By designing rooms that can be rapidly re-purposed, but are not unnecessarily redundant, the hospital can adapt more easily as situations change, perhaps improving safety and reducing costs" (Bosch \& Wears 2013: 8). Resilience engineering should also be used to address questions of technological infrastructure - for instance, the way "IT, including information systems and infusion devices, can be created so they can adapt to the fluid, variable clinical health care work setting" (Nemeth et al. 2008: 8). Other suggestions concern the production of new safety management tools by remodelling alreadyestablished technologies, such as the Root Cause Analysis, so they become better at "reflecting resilience concepts" (Sheps \& Cardiff 2011: 155). Another suggestion includes inventing new types of measurement, improvement and prediction tools that can support the ability to foresee, cope with and recover from errors (Jeffcott et al. 2009; Hollnagel et al. 2013). This includes, for instance, the Functional Resonance Analysis Method (FRAM) developed by Erik Hollnagel (2012), a model for risk assessment in complex systems based on an analysis of the 'functional resonance' arising from everyday performance variability. The main goal of the model is "to represent and understand the dynamics of complex socio-technical systems" (Hollnagel 2012: 89) by describing the main functions of certain activity to propose ways of managing the possible "occurrences of uncontrolled performance 
variability" (2012: 87). Hollnagel's model is based on a situated separation argument stating that while

2 linear accident models are still useful in situations where activities are regular and homogeneous, the

3 FRAM model is to be used when accidents occur "as emergent and nonlinear outcomes of dynamic 4 system processes" (2012: 88).

5 Finally, some suggestions are aimed at implementing more centralised management functions to ensure 6 the spread of resilience thinking in the organisation. In one paper, it is suggested, for instance, that an 7 'Interprofessional Safety Performance Department' should be established in hospitals. Such a 8 department "should be acquainted with the concepts of high reliability, resilience, and have 9 investigative skills congruent with the 'new view"' (Sheps \& Cardiff 2011: 155).

10 What the proposed resilience technologies seem to have in common, at least in their current form, is 11 that they do not seem radically different from the type of solutions that are considered useful safety 12 solutions in the Safety I toolbox. This includes the prospect of safety initiatives quickly being integrated 13 into a productivity agenda where it is claimed that resilience can provide "the means for organizations 14 to target resource investments by integrating safety and productivity concerns" (Nemeth et al. 2008: 1). 15 As well as the prospect of becoming part of the dominant 'measure-and-manage orthodoxy' (Waring 2009) of conventional patient safety thinking by substituting the measuring of errors (incident reporting) with the measuring and monitoring of performance variability and possible 'drifts into failure' (Jeffcott et al. 2009; Hollnagel 2012; Hollnagel et al. 2013), more importantly, they are both instances of safety science. By conceiving of a healthcare system's characteristics as certain in some sense (whether as stable and simple or changing and complex), the separation of stability and change helps pave the way for a shared interventionist faith in the value of system engineering performed by safety specialists, a discipline of which the most prominent authors of both Safety I and Safety II literature are themselves part.

\section{Problems of separation, certainty, and experience}

The paper proceeds with identifying three types of problems that the dichotomising tendencies of newer modes of patient safety engineering pose: the problems of separation, certainty and experience. The problem of separation is most evident in the substitution arguments (historical and ontological) of Safety II, but as I have argued, the situated position - although more nuanced than the substitution arguments - is also often based on faith in the possibility of easily separating simple settings characterised by low variance, predictability, and continuity from settings characterised by high variance, flexibility and complexity. Accordingly, to ascribe safety management tools that increase 
control, standardization, and formalization to the first of these settings while maintaining that the second type of settings requires safety management tools that promote loose coupling, flexibility, innovation and experimentation. This way of thinking is too simplistic to capture all organizational reality, as the dualistic nature of the argument undermines situations in which change or variation enable stability as well as those in which stability enables change; it neglects the way in which "change gives meaning to permanence and recurrence makes novelty possible" (Dewey 1925: 47). This is not new to safety literature, and it has been shown, for instance, that variation in terms of risk taking as well as learning through failure and trial-and-error can foster safety and stability (Wildavsky 1991). Safety II's quest to embrace performance variation by studying the way "care is delivered so well, so often, under difficult and varying conditions" (Braithwaite et al. 2015: 420; see also Mesman 2008) is, in itself, based on the realization that variance-inducing processes are often the basis of stable and reliable outcomes. Conversely, we must also challenge the often-uttered idea that while stability might provide short-term advantages in terms of, for instance, efficiency, it creates a rigid system that is largely incompatible with change. As noted by Farjoun, organisation theory is full of examples of cases in which "adaptability is supported by a considerable amount of structure and a number of stable mechanisms, as well as a surprising degree of formalization and strict control" (2010: 211; see also Pedersen 2013). In line with this, Holmes (2009) has argued that emergency nurses are able to act promptly, efficiently and innovatively exactly because of their strict adherence to rules and protocols in emergency situations: it is the stability of the rules, habits and routines that provides them with an 'artificial cool head' (Holmes 2009: 302), prevents them from overconcentration, helps them coordinate their responses and, not least, alert them to unintended complications. This comes interestingly close to Dewey's notion of habits, which is exactly based on the insight that oftentimes, variance-inducing outcomes rely on variance-reducing processes. In a description of how intelligent habits and training enable a violin player to play his violin both skilfully and creatively, Dewey argues that " $[\mathrm{m}]$ echanism is indispensable. If each act has to be consciously searched for at the moment and intentionally performed, execution is painful and the product is clumsy and halting" (Dewey 1922: 71).

It is not only the interconnectedness and mutual dependency of stability and change that are at risk of being ignored when stability and change is separated to pave the way for safety experts to optimise the healthcare system. Alongside the important problem of separation in the safety science approach to 30 patient safety, a connected problem emerges concerning the time-dependent and uncertain character of 31 safety work and clinical practice. The problem of uncertainty is evident in the fact that stability or change and predictability or unpredictability often cannot be presupposed at any given time; mundane 
1 decisions, providing medical diagnoses and designing treatment plans are all necessarily developing and emerging practises. Dewey defines clinical decision-making as an archetype of pragmatic reasoning based simultaneously on established procedures, previous experience, habit and situated case-based inquiry. He further states that "recognized procedures indicate to the physician what inquiries to set on foot for himself, what measures to try. They are standpoints from which to carry on investigations" (Dewey 1916: 171). Although evidence-based medicine has changed medicine drastically since 1916, the general acknowledgment that medical knowledge is inherently uncertain is still viable because, as a practical and case-based field, medicine is always dependent on the trajectory of the individual patient. This does not entail that medical knowledge is fundamentally unstable, complex and fluctuating, but because of the case-based and time-dependent character of medical knowledge and practice, it is never possible to know with certainty whether a particular diagnosis is final, whether a procedure will produce the desired result, whether a patient will follow the treatment plan or whether an apparently stable and safe situation remains so (Pedersen 2013). This insight is immensely important for patient safety, but it is not given credence when safety thinking is based on the simple assumption that healthcare can be divided into stable, ordered, predictable settings and unstable, complex, and unpredictable settings. The way this division should occur is also rarely discussed.

This leads us to a third shared problem of Safety I and II, namely, what can be determined as a problem of experience. For Safety I, experience constitutes an obvious problem, as the quest is largely to overcome variation through reducing the reliance on individual memory, experience and training. Resilience literature is more ambivalent in regard to the question of habits, experience and training. On the one hand, resilience engineers seek to embrace human variability and not treat healthcare professionals as 'fallible machines' (Hollnagel et al. 2013: 8). On the other hand, an often-repeated message is that in a constantly changing and complex world, we cannot rely on our past experiences: "We are consequently constrained to look at the future in the light of the past. In this way our experience or understanding of what has happened inevitably colours our anticipation and preparation for what could go wrong and thereby holds back the requisite imagination that is so essential for safety" (Hollnagel et al. 2006: 2). This argument resembles that of organisational theorist and safety researcher Karl Weick, who holds that to remain safety-conscious in a constantly changing environment, people are to 'drop their tools', i.e., their overlearned habits, skills and earlier experiences, and instead should improvise, innovate and be creative 'bricoleurs' in the moment (Weick 2007).

31 Likewise, when errors are understood as resulting from the complex interplay of systemic components, 32 individual (or team-based) decision-making is not necessarily of significance to the outcome of actions: 
incompetence or error. Instead, both owe their occurrence to a mostly unpredictable, but not unimaginable, combination of a number of system characteristics" (Hollnagel et al. 2013: xxiv). Thus, it is argued that in a complex and fluctuating system, the time span and influence of experiences, habits and decision-making are short lived and, consequently, that system safety is the better way forward. As noted by Zuiderent-Jerak and Berg (2010), it is the conception of safety as a system property that lays the groundwork for inviting safety science experts and complex system engineers to scrutinize and observe the system 'from the outside'. As such, the system engineering perspective on safety ultimately questions the internal self-regulation and safety management of healthcare professionals in two important ways: first, by questioning the habits, training and experience of healthcare professionals and second, by making expertise in system design a precondition for patient safety.

\section{Overcoming the paradox of stability and change: A few reflections on sociological alternatives}

In this final discussion of the paper, I turn to some of the older and more recent sociological perspectives on patient safety. The goal is not to give a comprehensive account of these alternatives but to present a few snapshots to indicate what has already been done to resolve the paradox of stability and change in mainstream healthcare quality and patient safety literature.

In a quest to rethink and nuance the understanding of formalisation, rules and standards in healthcare, a number of authors within Science and Technology Studies have turned specifically to the relationship between stability and change by introducing new categorises such as 'flexible standards' (Timmermans and Berg 2003), 'situated standardisation' (Zuiderent-Jerak 2007, 2015) and 'flexible systematization' (Iedema and Carroll 2011). At times, these studies opt for a separation of stability and change not unlike that of the situated separation arguments of the resilience literature. In The Gold Standard (2003), Timmermans and Berg argue that

"In redesigning care processes, standardization should thus be localized in only some specific parts of the health care process (e.g., routine diagnostic tests, repeated aspects of therapeutic trajectories, recurring triage moments, etc.). In other aspects of the health care process, possible variation should be embraced." (2003: 210)

Similar to this argument, Zuiderent-Jerak argues that situated standardisation "tries to empirically elucidate specific issues in care delivery so that an assessment can be made, of which aspects of the organization of care should be given space and which aspects should be standardized" (Zuiderent-Jerak 2015: 72). This type of reasoning is echoed in Iedema and Carroll's notion of 'flexible systematization' that is presented to promote the institutionalisation of reflexive spaces in healthcare practices by 
1 introducing an 'outsider-catalyst' to allow healthcare practitioners to problem-solve complex patient safety issues (Iedema and Carroll 2011).

3 Simultaneously, however, other parts of these writings take important steps in the direction of providing a more pragmatic and less dichotomised perspective on change and stability by recognising the time-dependent and developing character of medical practice. Timmerman and Berg opt for the possibility of flexibility being built into the standards, arguing that "[f]lexibility implies that the system is not more detailed than required, nor more stringent than necessary, nor more imperative than usable" (2003: 211). In line with Dewey (1922) and later work on the flexibility of routines (Feldman \& Pentland 2003; Cohen 2007), this implies that a standard can be revisited and adapted whenever new local demands or new types of evidence suggest the need for such adaption: "a standardized protocol's strength depends on the extent that the tool allows for deviation and improvisation" (Timmerman \& Berg 2003: 211). This position also acknowledges the way in which clinicians' situated use of standards, guidelines, and protocols often require workarounds to complete the task (Iedema \& Carroll 2011). A more pragmatic understanding of the relationship between standards and flexibility is also the core of Zuiderent-Jerak's notion of 'situated standardization', which he introduces to "contribute to a more processual understanding" of the development of standards, guidelines, and quality improvements in healthcare (Zuiderent-Jerak 2007: 326), as well as to bypass what he determines as the dichotomy between universal standardisation and individualised medicine. From Zuiderent-Jerak's perspective, standards are not to be 'implemented' but must instead be continuously developed and locally renegotiated (Zuiderent-Jerak 2015: 92). By presenting us with a processual, time-dependent and adaptable concept of standardisation, these sociological perspectives highlight the uncertainty of medical practices and thereby challenge the problem of certainty.

In a particularly informative description of the problem of certainty in safety management, JerakZuiderent mobilises a distinction between 'certain unsafety' and 'uncertain safety' (2012). Her study shows how Safety I's standardised knowledge is superimposed as part of safety solutions and the way in which this potentially has serious consequences for clinical judgments and the lived and located judgement' of how safe care should be understood in concrete situations (Jerak-Zuiderent 2012: 16). The certainty with which the standardised knowledge is promoted might have unsafe consequences, while a more 'uncertain' attitude that takes into account, for instance, the possibility of error is more likely to accommodate safety (2012: 16-17). Although Jerak-Zuiderent's argument is directed at the 31 Safety I position, the critique of the prescriptive and 'certain' character of safety science and technology can be expanded to include the most prescriptive parts of Safety II, where the complexity, change and 
1 fluidity of present healthcare systems (or parts of these systems) are presupposed; to predetermine unpredictability may have the same 'certain unsafety' type of consequences as when predictability is

3 predetermined.

4 To grasp the importance of the theme of uncertainty for patient safety, one of the best places to turn is some of the work that is done on patient safety and medical error in medical sociology before the introduction of safety science and system engineering in healthcare. An early example is medical sociologist Rene Fox's article from 1957 entitled "Training for Uncertainty". As the title suggests, Fox argues that medical training largely focuses on learning to cope with uncertainty through the development of a so-called "philosophy of doubting" (Fox 1957: 219). Physicians are trained to act with the inherent uncertainty of medical practice through fostering a necessary "manner of certitude" (Fox 1957: 227) that enables them to commit to their clinical judgements and act decisively on behalf of their patients while also bearing the ever-present possibility of error in mind. This theme of acting with uncertainty is also the focal point of Marianne Paget's The Unity of Mistakes (1988), where the possibility of the medical mistake, understood as a mis-take or an action-becoming-wrong, constitutes the primary moral tension of medical practice. Because of the situated and time-dependent character of medical knowledge, the physician is obliged to act resolutely while acutely aware that his decisions may be wrong. Paget labels this dimension of medical work 'acting-as-if' (1988). By addressing uncertainty as a condition that cannot be discarded because of "the essential developmental nature of clinical work" (Paget 1988: 27), these early studies are in line with the more processual parts of the situated standardisation arguments presented above. Furthermore, they accentuating the healthcare professionals' necessary training to act in the face of uncertainty and focus on the experiences, habits and dispositions in handling safety in healthcare. This is also a main theme in Jessica Mesman's Uncertainty in Medical Innovation, where she specifically focuses on identifying "how actors succeed in acting promptly and adequately in situations of uncertainty and doubt" (2008: 8). She also identifies the particular competences that are to be taught and fostered to enable such safety-conscious action, including "routines, clinical experience, skills, knowledge" (Mesman 2008: 81). By bringing the experiences, habits and safety dispositions of healthcare professionals back into focus for patient safety, these perspectives on uncertainty are important in terms of supplementing the system engineering position.

\section{$30 \quad$ Conclusion}

31 The new resilience approach to safety management is immediately attractive. It encompasses relevant 32 critiques of conventional patient safety thinking, and it contains important claims about how to think 
differently about safety, not least in terms of acknowledging the necessity of performance adjustment and variability in maintaining safe care. The more situated parts of the literature, which also largely echo some of the newer sociological alternatives to patient safety, may prove to have an important function in insisting on more localised and adaptive practices of safety management. However, the new school of patient safety also comes with a number of assumptions, challenges and problems that are not unlike those of the orthodox view. In this paper, I have shown that as oppositional and dichotomised strands of patient safety, Patient Safety I and II are largely constituted in relation to a paradox of stability and change that allows for the interventionist safety science and system engineering optimism of both positions. Within a general frame of Dewey's pragmatism, I have discussed the assumptions and arguments on which this paradox is based as well as some of the problems it causes. This includes a problem of separation, which is argued in ontological, historical or situated terms within the Safety II perspective and includes a simplified idea that control systems and standards are useful in stable, linear, and simple systems while flexibility, slack, and variation are necessary in complex and fluid systems. While the situated parts of this argument are preferable to ontological and historical substitution arguments, it is still too simplistic to capture the organisational reality of healthcare, where variation often has stable safety outcomes while standards, rules, and habits can function as preconditions for the creativity, flexibility, and adaptability needed to obtain safety in, for instance, emergency situations. Moreover, the assumption that healthcare settings can be meaningfully separated into predictable settings that are characterised by low variance and complex settings that are characterised by high variance presents a problem of certainty because it fails to take into account the time-dependent, developing and therefore uncertain nature of medical knowledge, clinical decision-making, and care situations. Finally, the paper points to a shared questioning of training, habits and experience in Safety I and II, which helps pave the way for system engineering while simultaneously moving responsibility and expertise from the healthcare professional to safety science experts in matters of patient safety. One way to challenge this problem of experience is to refocus attention on the importance of the development of healthcare professionals' 'safety dispositions', which are to be based on habits, training and experience in acting with uncertainty.

\section{Bibliography}

Bosch, S.J. and Wears, R.L. (2013) Resilience engineering: A better way of approaching patient safety? Edra Connections, May 2013, 7-9.

Braithwaite, J., Wears, R.L. and Hollnagel, E. (2015) Resilient health care: Turning patient safety on its head. International Journal for Quality in Healthcare (2015), 27, 5, 418-420. 
1 Cohen, M. D. (2007) Reading Dewey: Reflections on the study of routine. Organization Studies, 28, 7732786.

3 Dekker, S. (2011) Drift into Failure: From Hunting Broken Components to Understanding Complex Systems.

4 Burlington VT: Ashgate Publishing.

5 Department of Health. (2000) An Organisation with a Memory: Expert Group Report. London: Department 6 of Health.

7 Department of Health. (2001) Building A Safer NHS For Patients: Implementing an Organization with a 8 Memory. London: Department of Health.

9 Dewey, J. (1916) Democracy and Education: An Introduction to the Philosophy of Education. First paperback 10 edn., 1966, New York: The Free Press.

11 Dewey, J. (1917) Duality and Dualism. The Journal of Philosophy, Psychology and Scientific Methods, 14, 18, $12 \quad 491-493$.

13 Dewey, J. (1922) Human Nature and Conduct: An Introduction to Social Psychology. New York: Promentheus 14 Books.

15 Dewey, J. (1925) Experience and Nature. Reprint 1958, New York: Dover Publications.

16 Du Gay, P. and Vikkelsø, S. (2012) Reflections: The lost specification of 'change'. Journal of Change 17 Management, 12, 2, 121-143.

18 Feldman, M. S., and Pentland, B. T. (2003) Re-conceptualizing routines as a source of flexibility and 19 change. Administrative Science Quarterly, 48, 94-118.

20 Farjoun, M. (2010) Beyond Dualism: Stability and Change as a Duality. Academy of Management Review, $2135,2,202-225$. Fox, R. (1957) Training for Uncertainty. In: Merton, R.K., Reader, G. and Kendall, P.L. (eds.) The Student-Physician: Introductory Studies in the Sociology of Medical Education. Cambridge, Mass: Harvard 24 University Press, pp. 207-241.

Hale, A. (2014) Foundations of safety science: A postscript. Safety Science, 67, 64-69.

26 Harris, F. (2007) Dewey's Concepts of Stability and Precariousness in His Philosophy of Education. Education and Culture, 23, 1, 38-54. 
1 Holling, C.S. (1973) Resilience and stability of ecological systems. Annual Review of Ecology and Systematics, $24,1-23$.

3 Hollnagel, E. (2012) FRAM: The Functional Resonance Analysis Method: Modelling Complex Socio-Technical Systems. Surrey, UK: Ashgate Publishing Ltd.

Hollnagel, E., Woods, D.D. and Leveson, N. (2006) Resilience Engineering: Concepts and Precepts. Aldershot: 6 Ashgate Publishing.

Hollnagel, E., Braithwaite, J. and Wears, R. (eds.) (2013) Resilient Health Care. Surrey, UK: Ashgate 8 Publishing Ltd.

9 Hollnagel, E., Wears, R. and Braithwaite, J. (2015) From Safety-I to Safety-II: A White Paper. The Resilient Health Care Net, Published by the University of Southern Denmark, University of Florida, USA, and Macquarie University, Australia.

Holmes, S. (2009) In Case of Emergency: Misunderstanding Tradeoffs in the War on Terror. California Law Review, 92, 2, 301-356.

14 Iedema, R. and Carroll, K. (2011) The "clinalyst": Institutionalizing reflexive space to realize safety and 15 flexible systematization in health care. Journal of Organizational Change Management, 24, 2, 175-190.

16 Jeffcott, S., Ibrahim, J. and Cameron, P. (2009) Resilience in healthcare and clinical handover. Quality 17 and Safety in Health Care, 18, 256-260.

18 Jensen, C.B. (2008) Sociology, systems and (patient) safety: Knowledge translation in healthcare policy, 19 Sociology of Health \& Illness, 30, 2, 309-324.

20 Jerak-Zuiderent, S. (2012) Certain Uncertainties: Modes of Patient Safety in Healthcare. Social Studies of 21 Science, 42, 5, 732-752.

Kohn, L.T., Corrigan, J.M. and Donaldson, M.S. (eds.) (2000) To Err is Human: Building a Safer Health System. Committee on Quality of Healthcare in America, Institute of Medicine. Washington D.C.: 24 National Academy Press. perspectives on organizational learning. Organization Science, 17, 502-513. 
1 March, J. G. (1991) Exploration and exploitation in organizational learning. Organization Science, 2, $71-$ 287.

3 McDonald, R., Waring, J. and Harrison, S. (2006) Rules, safety and the narrativisation of identity: A 4 hospital operating theatre case study. Sociology of Health \& Illness, 28, 178-202.

5 Mesman, J. (2008) Uncertainty and Medical Innovation: Experienced Pioneers in Neonatal Care. Basingstoke, 6 UK: Palgrave Macmillan.

7 Nemeth, C., Wears, R., Woods, D., et al. (2008) Minding the gaps: Creating resilience in health care. In 8 Henriksen, K., Battles, J.B., Keyes, M.A. et al. (eds.) Advances in Patient Safety: New Directions and 9 Alternative Approaches. Vol. 3: Performance and Tools. Rockville, MD: Agency for Healthcare Research 10 and Quality.

11 Paget, M. (1988) The Unity of Mistake: A Phenomenological Interpretation of Medical Work. Philadelphia: 12 Temple University Press.

Pedersen, K.Z. (2013) Failsafe Organizing: A Pragmatic Stance on Patient Safety. PhD Series 32.2013, Doctoral School of Organisation. Copenhagen: Copenhagen Business School.

RHCN. (2016) Retrieved from www.resilienthealthcare.net. March 3, 2016.

Sheps, S.B. and Cardiff, K. (2011) Patient safety: A wake-up call. Clinical Governance: An International Journal, 16, 2, 148-158.

Sutcliffe, K. M., Sitkin, S. B., and Browning, L. D. (2004) Tailoring process management to situational requirements: Beyond the control and exploration dichotomy. In M. L. Tushman and P. Anderson (eds.) Managing strategic innovation and change. New York: Oxford University Press, pp. 178-191.

Timmermans, S. and Berg, M. (2003) The Gold Standard: The Challenge of Evidence-Based Medicine and Standardization in Healthcare. Philadelphia: Temple University Press.

Walker, J. and Cooper, M. (2011) Genealogies of resilience: From systems ecology to the political economy of crisis adaptation. Security Dialogue, 42, 2, 143-160.

Waring, J. (2009) Constructing and Re-Constructing Narratives of Patient Safety. Social Science \& Medicine, 69, 9, 1722-1731. 
1 Weick, K.E. (2007) Drop your tools: on reconfiguring management education. Journal of Management

2 Education, 31, 1, 5-16.

3 Weick, K.E., \& Quinn, R.E. (1999) Organizational change and development. Annual Review of Psychology, $450,361-386$.

5 Weick, K.E. and Sutcliffe K.M. (2007) Managing the Unexpected: Resilient Performance in an Age of Uncertainty, $6 \quad 2^{\text {nd }}$ edn. San Francisco: Jossey-Bass, Wiley.

7 Wildavsky, A. (1991) Searching for safety. New Brunswick, NJ: Transaction.

8 Zuiderent-Jerak, T. (2007) Preventing Implementation: Exploring Interventions with Standardization in

9 Healthcare. Science as Culture 16, 3, 311-329.

10 Zuiderent-Jerak, T. (2015) Situated Intervention: Sociological Experiments in Health Care. Cambridge and 11 London: The MIT Press.

12 Zuiderent-Jerak, T. and Berg, M. (2010) The Sociology of Quality and Safety in Healthcare: Studying a 13 Movement and Moving Sociology. In: Bird, C.E., Conrad, P., Fremont, A.M. and Timmermans, S. 14 (eds.) The Handbook of Medical Sociology, $6^{\text {th }}$ edn. Nashville, Tennessee: Vanderbilt University Press, pp. $15324-340$.

\section{Acknowledgments}

19 The author is thankful to Jessica Mesman who provided valuable comments and supportive suggestions 20 to an earlier version of this paper. I am also highly appreciative for the helpful critique and feedback 21 from the three anonymous reviewers and the editors Ian Rees Jones and Justin Waring. Further thanks 22 should go to Signe Vikkelsø and Paul du Gay who supervised the dissertation that has laid the groundwork for some of the arguments in this paper. 